\title{
Development of the method of direct temperature measurement for gear cutting of cylindrical gears by hob milling
}

\author{
Sandra Sovilj-Nikić ${ }^{1, *}$, Bogdan Sovilj ${ }^{2}$, Dušan Ješić ${ }^{3}$, Vladimir Blanuša ${ }^{4}$, Vladimir M. Tonkonogyy ${ }^{5}$, Liubov Bovnegra $^{6}$ \\ ${ }^{1}$ Iritel a.d. Beograd, Batajnički put 23, 11080 Belgrade, Serbia \\ ${ }^{2}$ University of Novi Sad, Faculty of Technical Sciences, Trg Dositeja Obradovica 6, 21000 Novi Sad, Serbia \\ ${ }^{3}$ International Technology Management Academy, Trg Dositeja Obradovica 7, 21000 Novi Sad, Serbia \\ ${ }^{4}$ High Technical School of Professional Studies, Školska 1, 21000 Novi Sad, Serbia \\ ${ }^{5}$ Odessa National Polytechnic University (ONPU), Shevchenko Avenue 1, 65044 Odessa, Ukraine \\ ${ }^{6}$ Odessa National Polytechnic University (ONPU), Shevchenko Avenue 1, 65044 Odessa, Ukraine
}

\begin{abstract}
The availability, adaptability, reliability and productivity of modern industrial complexes, maintenance costs, energy costs and industrial production costs depend also on the intensity of wear of the elements of tribo-mechanical systems. Gear cutting operations are usually a bottleneck of production, especially in higher types of production. Therefore, the necessity of researching the process of gear cutting by hob milling is obvious. In the paper a part of the results related to the possibility of direct measurement of the temperature in a very complex process of gear cutting of cylindrical gears by hob milling is given.
\end{abstract}

\section{Introduction}

The rapid development of industrial production in the world has caused the need for extensive research in all areas, even in the field of machining.

Hob milling, as one of the most complex machining processes, has the widest application in the gear cutting of cylindrical gears due to the high productivity of the process. In Fig. 1 [1], the principle of hob milling and kinematics are shown.

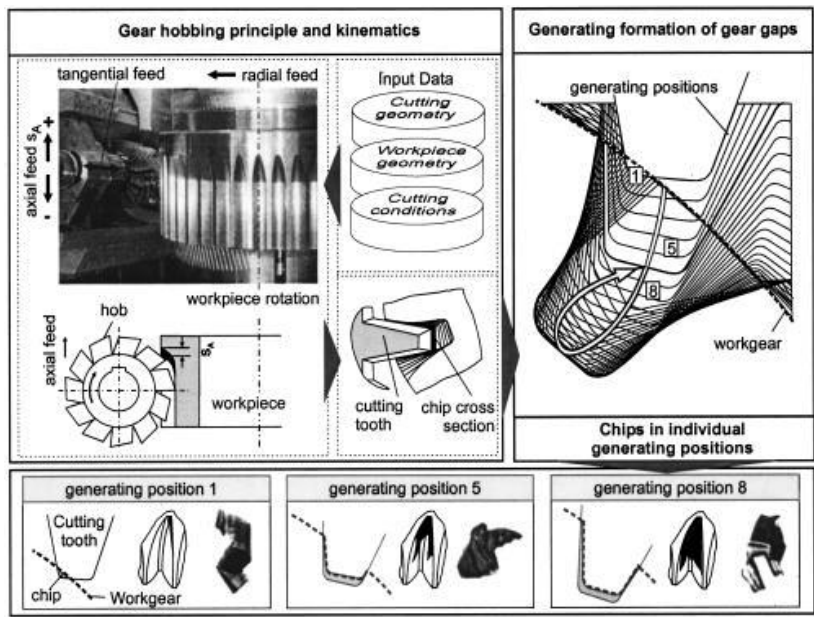

Fig. 1. Hob milling principle and kinematics

The complicated kinematics and geometric relations between the hob milling tool and the work-piece create a series of difficulties and problems that prevent the optimal use of tool and machine (Fig 2 [2]).

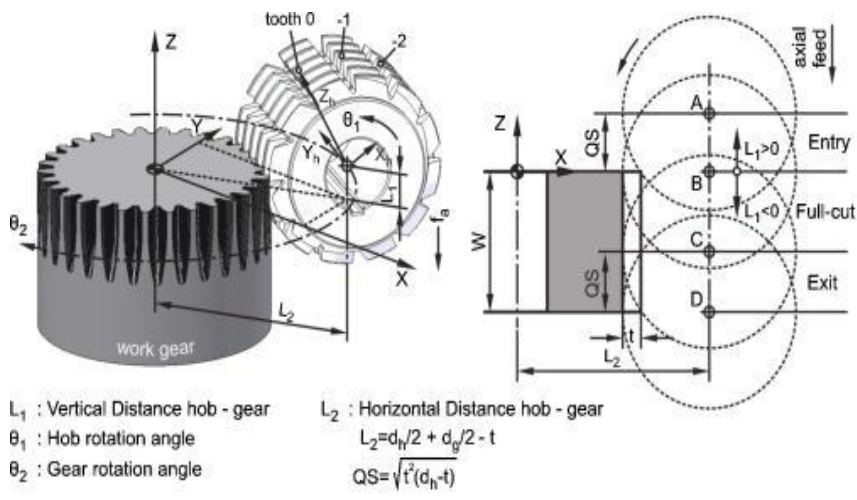

Fig. 2. Hob milling kinematics

Most of the hob milling tools can be classified into three groups according to their design (Fig. 3.a [3,4]). All of the aforementioned hob milling tools can be coated. The hob milling tools with changeable teeth or strips from high speed steel, cemented-carbide or sintered alloy consist of a basic body made of cheaper material and are particularly suitable for larger diameters and larger modules. The hob milling tools with changeable teeth beside that they allow larger constructive back angles, they also have a relatively large, usable cutting length.

Various variants of hob milling tools that combine different processes such as roughing and finishing and machining of chamfers for removing irregularities (Fig. $3 \mathrm{~b}$ $[3,4])$ have also been developed. In order to increase the productivity of the hob milling, gear cutting process is very close to the limit of the technological capabilities of the machine tools and the hob milling machines. Therefore, the optimal choice of the hob milling tool material is important in achieving this goal.

* Corresponding author: sandrasn@eunet.rs 


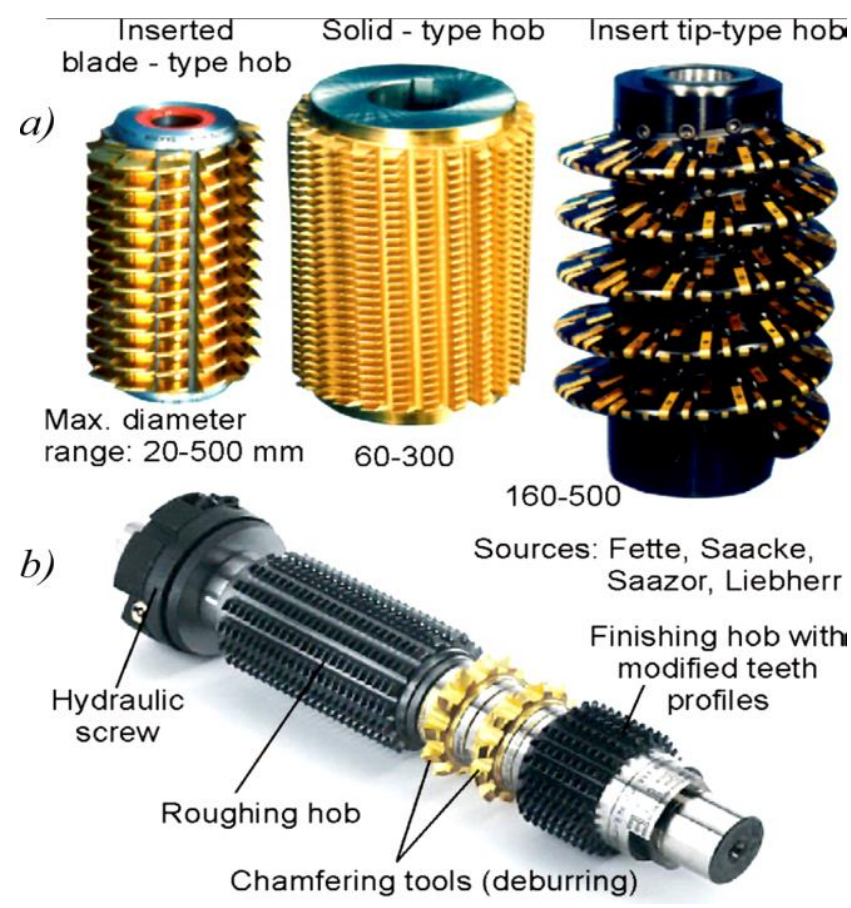

Fig. 3. Modern hob milling tools

In Fig. 4 [5], the influential parameters on the process of wear of hob milling tool are given. Hob milling is a multiparametric and complex method for the gear cutting of cylindrical gears.

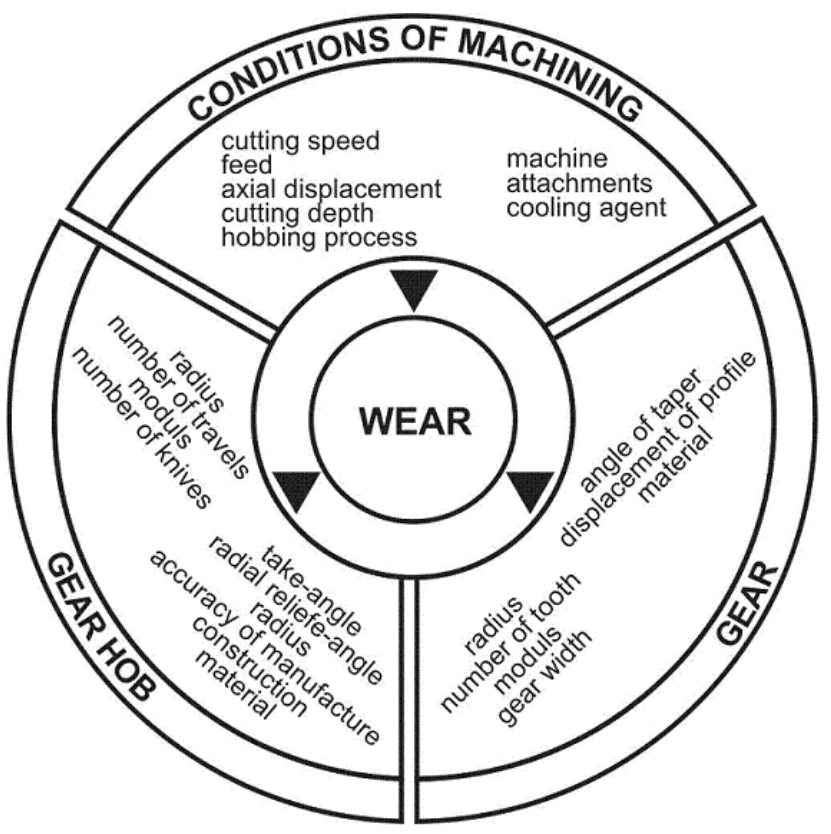

Fig. 4. Influential parameters on wear process of hob milling tool

A comprehensive knowledge of the gear cutting process is crucial for solving the demands of the global market. The world market today is being tackled with rapid and continuous changes. Fig. 5 [6] shows a production environment in the 21 st century. A number of factors affecting the world market can be seen in the Figure.
Production operations and methods of gear cutting in mass production depend on various parameters such as cost of gear cutting, production philosophy, practical experience, etc. A common strategy is to achieve the highest possible accuracy during rough gear cutting and to perform thermal treatment with the necessary tolerance to completely avoid finishing the serration [4].

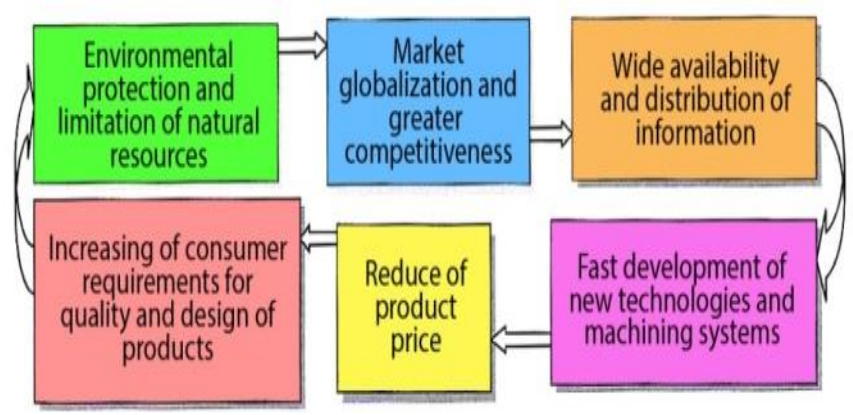

Fig. 5. Manufacturing environment in 21 st century

Many physical and chemical reactions that occur in the process of gear cutting by hob milling and are directly related to the wear of hob milling tool, are largely dependent on the temperature at which they occur, whether it is the speed of their advancement or achieving the balance. It is obvious that the reasons for measuring the temperature are numerous [7].

\section{Thermal phenomena in hob milling}

The research of the thermal phenomena due to mentioned in previous section is one of the key problems in the gear cutting by hob milling. Knowledge of the basic principles on which the layout of the heat sources and the character of the temperature field in the hob milling tool, workpiece and chip are based, enables a better formulation of the basic theory of the chip formation and other phenomena characteristic for the process of gear cutting by hob milling.

The scope of the method for the research of the chip formation in the gear cutting by hob milling is given in Fig. $6[4,8]$.

Fig. 6 also shows areas in which the knowledge about the chip formation in the hob milling can be applied. The fields of application of the knowledge of the chip formation are widespread according to the direction of the evaluation of the cutting properties of the tools for gear cutting and materials of the hob milling tools, the machining economy, the conditions in the gear cutting on modern hob milling machines, the use of cutting fluids in the gear cutting, etc.

The theory of gear cutting, especially the part dedicated to the chip formation, is always conceived of knowledge and experimental procedures. Experimental methods are the source of the a priori data and information used to verify the set modeling procedures, which are shown in Fig. 7, 8 and 9 [4,8]. 


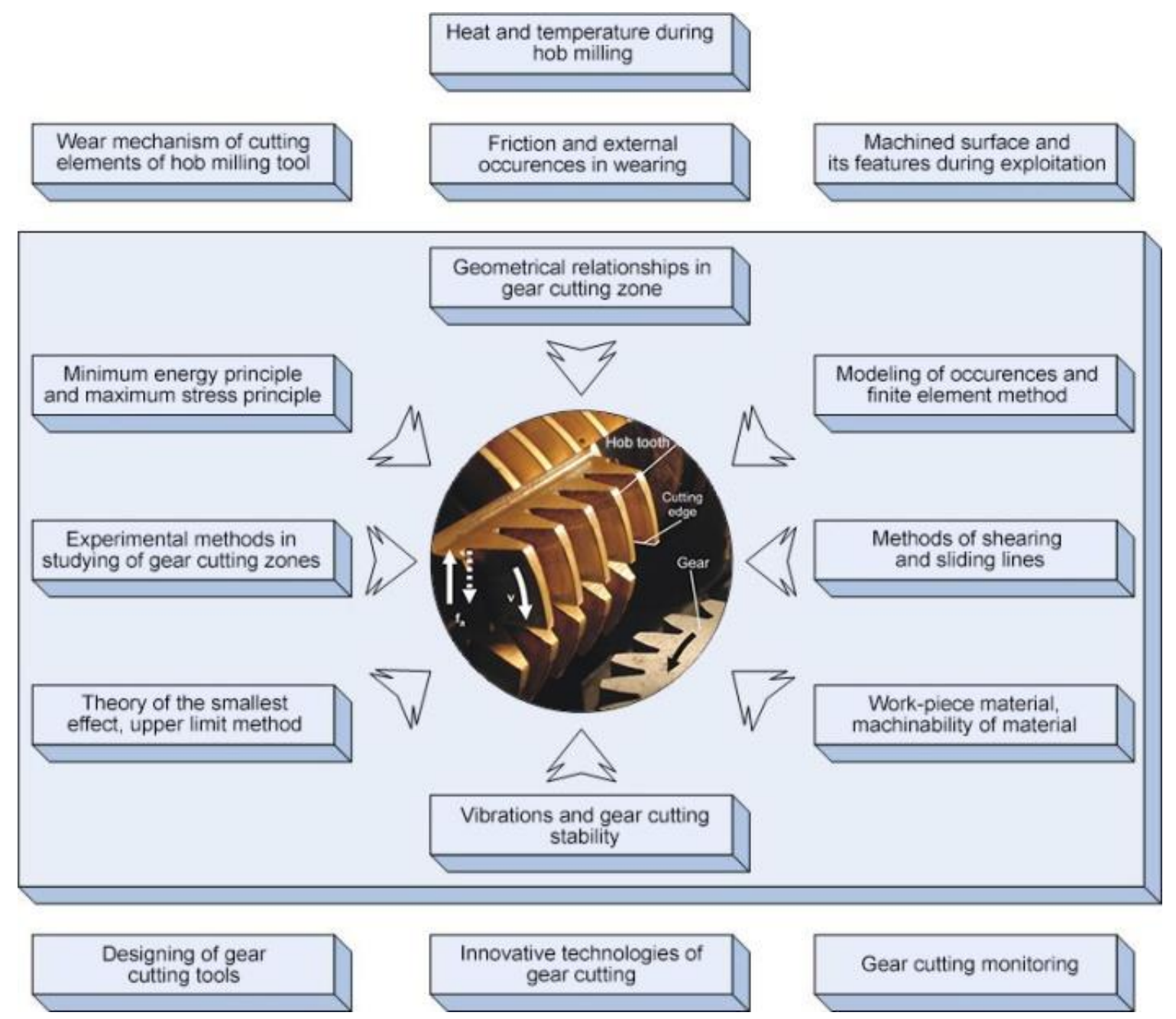

Fig. 6. Methods and procedures in the scientific approach to the research of the chip formation in gear cutting by hob milling

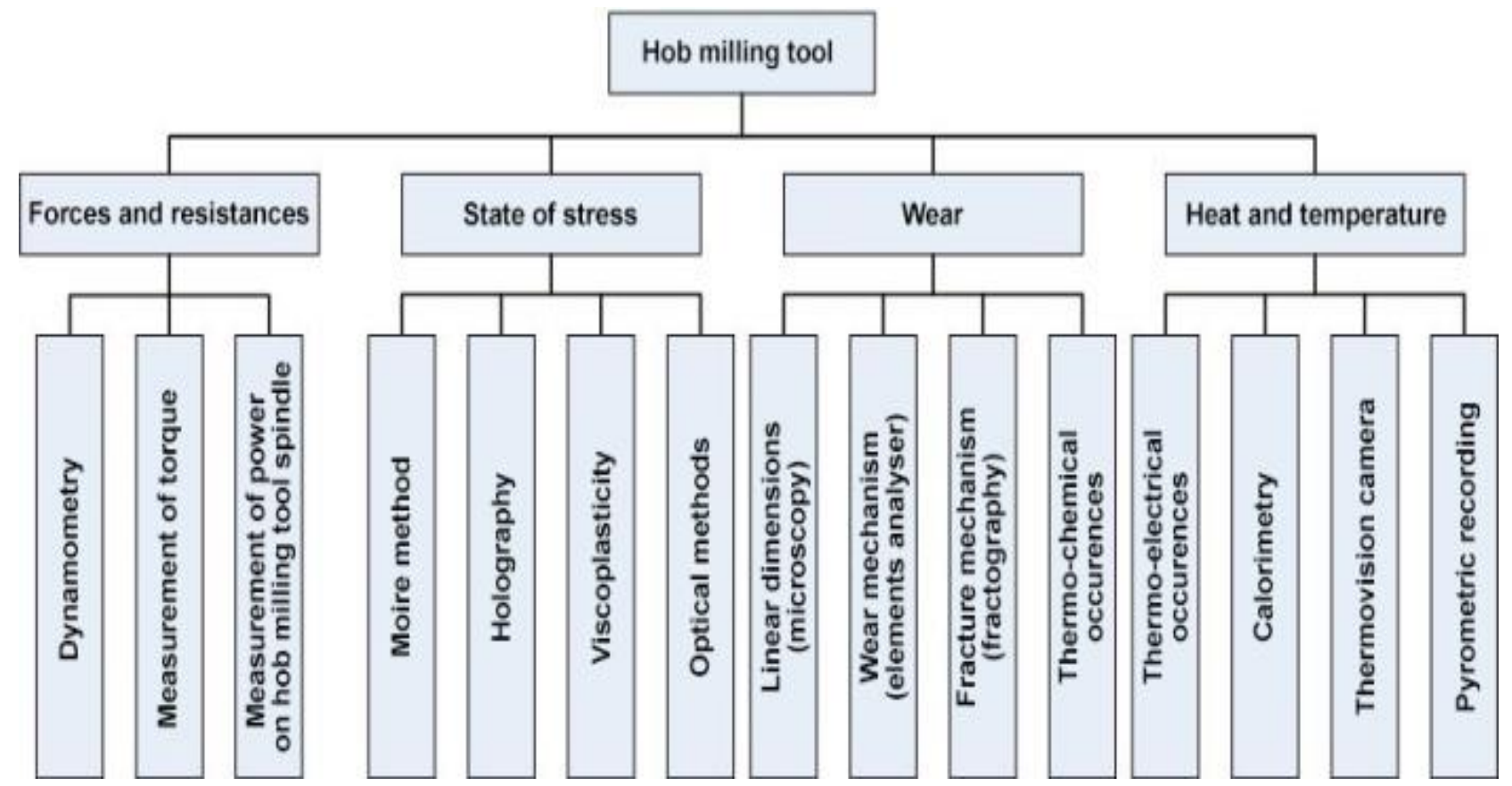

Fig. 7. Overview of the main experimental methods and procedures in cutting theory with regard to the cutting tool 


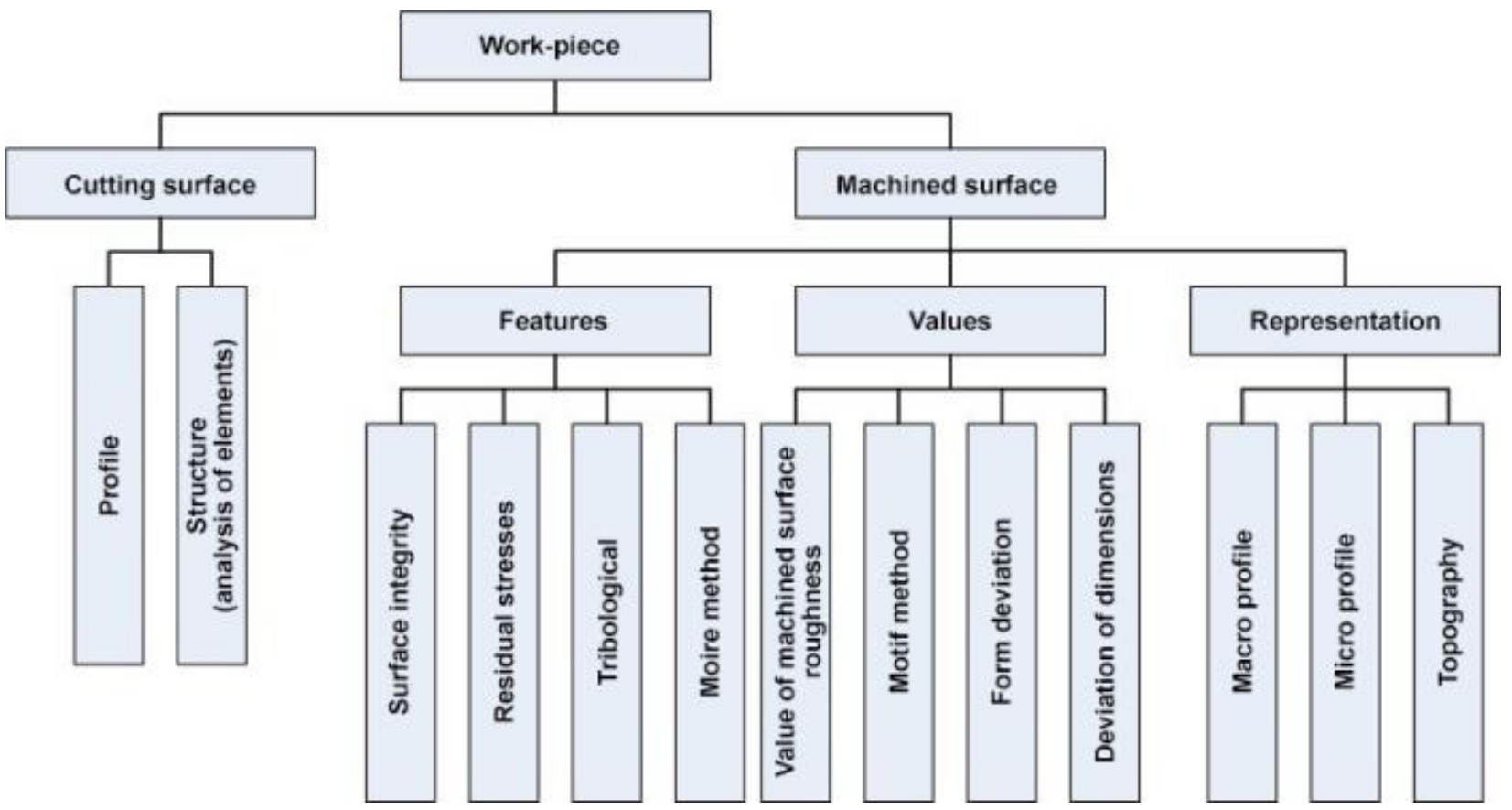

Fig. 8. Overview of the main experimental methods and procedures in cutting theory with regard to the work-piece

The scale of the experimental methods used is wide. In their application, the goal and availability decide. More procedures require special devices (for example, cutting failure) that are most often protected by patents.

Standardized methods for measuring surface roughness, stiffness of hob milling machines nodes, ISO standards and testing of cutting tools abilities are known, etc., but there are requirements for acquiring new knowledge that lead to new and unique measurement procedures. The overview shown in Fig. 7, 8 and 9 can be considered as orientation and can be further addressed in iterative procedures. They always refer to pairs of observation objects (for example a chip-hob milling tool, for example: for examining a surface contact, i.e., a real surface of the contacts, a shear surface of chip, etc.). A similar situation occurs in the case of a pair of hob milling tool- workpiece, where it is possible to test the dependence of the tool life, the machinability of the material and the cutting ability for gear cutting.

Contemporary gear cutting technology includes also finishing processes, which give the final shape of gear serration, determine the successive position of the surfaces, the accuracy and quality of their manufacture. For these reasons, it is very important to know all the processes and phenomena that have a significant impact on the resulting accuracy and quality of products to ensure effective production.

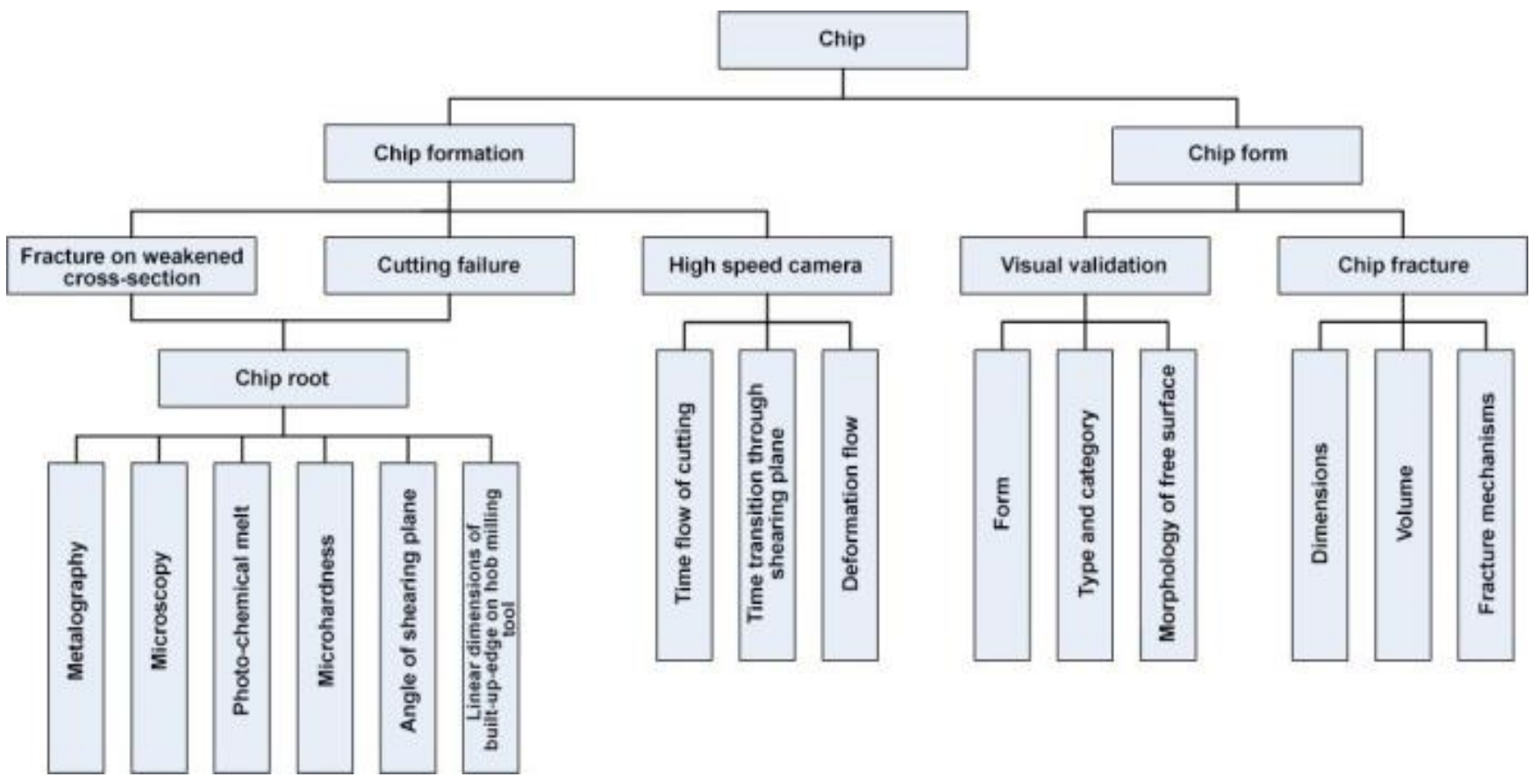

Fig. 9. Overview of the main experimental methods and procedures in cutting theory with regard to the chip 
In addition to the above, the knowledge of the basic principles on which the layout of the heat sources and the character of the temperature field in the hob milling tool, work-piece and chip are based enables: the correct formulation of the basic theory of the tool life of the hob milling tool, as well as predicting the wear character and the degree of its intensity under different machining conditions; the correct formulation of the requirements for new materials of the hob milling tool that would allow the application of optimal parameters of the cutting regime; the evaluation of the cutting fluids in the gear cutting process, and the proper formulation of requirements for new more efficient cutting fluids, including their proper application; the application of the

results of the study of thermal phenomena in order to reduce the harmful effect of temperature on the workpiece, especially on its surface layer; determining the heat stresses in the cutting elements of the hob milling tool and their changes in time, in order to could evaluate their impact on the sudden fracture of the cutting elements of the hob milling tool; the improvement of the existing construction of the hob milling tools from the point of better drainage of the thermal energy, ie, the reduction of wear; the development of sensors for adaptive control of the hob milling machines in order to optimize the machining process using the influence of temperature on the tool life of the hob milling tool and the quality of the machined surface.

In this paper, the basis for the method of direct measurement of temperature in the gear cutting of cylindrical gears by hob milling is given.

\section{The method for direct temperature measurement during hob milling of serration}

Due to the great importance that knowledge of the temperature has in the process of gear cutting by hob milling, the need for the development of a new simpler, more reliable and accurate measuring method was imposed, which would operate on a direct principle. This can be achieved using miniature thermocouple whose external diameter of the protective coating is $0.5 \mathrm{~mm}$ and less.

In Fig. 10 a schematic diagram showing the principle of measuring the cutting temperature when machining by hob milling according to the design solution is given. A sample of $20 \mathrm{CrMo} 5$ was used as a work-piece with the same characteristics as well as samples that were used to research optimal cutting regimes and optimal cutting geometry of the hob milling tool, but additional preparation was performed. The preparation consisted of drilling four holes $\Phi 15$ at a distance of $15.5 \mathrm{~mm}$ from the outer edge of the work-piece. On the outside, and at a distance of $2 \mathrm{~mm}$ from the forehead, the hole the diameter $\Phi=0.6 \mathrm{~mm}$ was drilled normal to the axis of already drilled hole $\Phi 15 \mathrm{~mm}$. The next hole was drilled at a distance of $30 \mathrm{~mm}$ from the first, i.e. $32 \mathrm{~mm}$ from the forehead, which is the place where the model hob milling tool completed the entire machining of gullet at a distance of $2 \mathrm{~mm}$ from the forehead. The first thermocouple is indrawn into the first hole, and the second thermocouple in the second hole. Therefore, the model hob milling tool proceeds completely out of

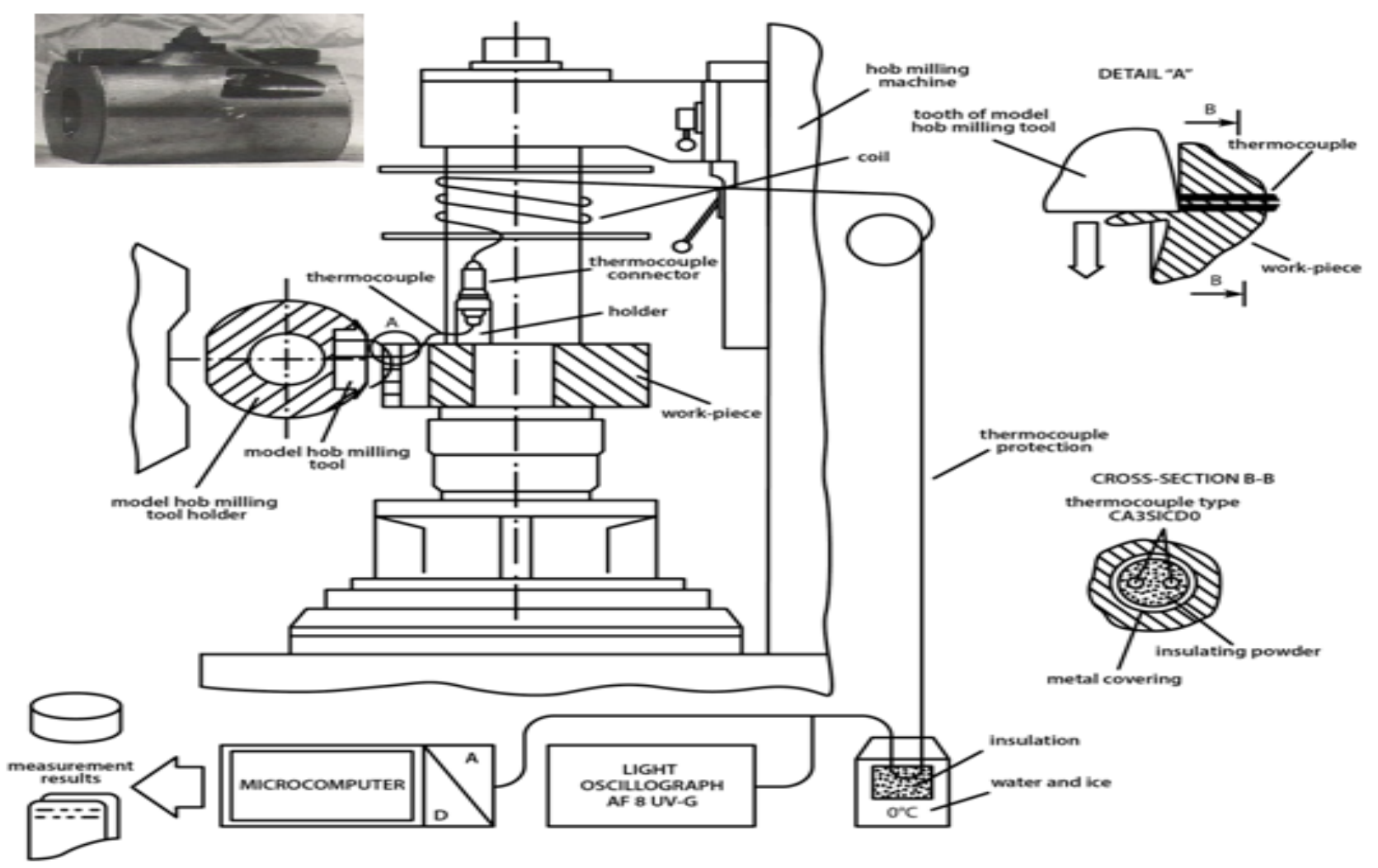

Fig. 10. Scheme of instrumentation used in measurement of temperature during hob milling 
contact with the first thermocouple and then, after its rotation, it contacts with another thermocouple.

From the "Thermocoax" series, a miniature thermocouple type CA 3 S 1000 has been selected with the following characteristics: thermocouple wire: $\mathrm{NiCr}-\mathrm{Ni}$ (Chromel-Alumel); polarity: (C $5000 \mathrm{~S}$ ) $\mathrm{NiCr}(+) \mathrm{Ni} \mathrm{(-);}$ the voltage characteristic and tolerance; thermo stress cca $41 \mu \mathrm{V} /{ }^{\circ} \mathrm{C}$; insulation: Magnesium Oxide MgO; external diameter: $0.5 \mathrm{~mm}$; diameter of the thermocouple wire: $0.08 \mathrm{~mm}$; protective sheath: stainless steel; thickness of protective sheath: $0.06 \mathrm{~mm}$; temperature range: 200 to 1200; minimum bending diameter: $0.5 \mathrm{~mm}$.

The length of the thermocouple is $1000 \mathrm{~mm}$, the length of the corresponding cable duct C5000S for the connection with the instrument is $5000 \mathrm{~mm}$, and the connection between the thermocouple and the cable duct is carried out with a special plug LBE1/LSA1. In Fig. 10, detail A, a thermocouple with a protective sheath of Philips Company is shown.

Two holders are placed on the sample, in which plugs are installed (thermocouple connection). The cable duct is connected by copper conductors connecting the thermocouple with the measuring instrumentation or the microcomputer system. The connection of cable duct and copper conductors is placed in a bowl with ice in order to maintain zero.

The AF8 UV-G light oscillograph was used as an instrument (Fig. 10). It is necessary for the new research to develop software support that will be compatible with the process of hob milling, since the existing one, which is used for the measurement of the mean temperature in the turning process, is not satisfied due to specific conditions.

The light oscillograph has a very sensitive galvanometer with electromagnetic silencer type GA 1,1/8H (Fig. 10).

Calibration was performed in order to translate the size of the deflections registered on the paper into the values for the thermo stress or temperature. It is achieved by means of the compensating instrument "Thermocontrol" type YHK, by which it can be very precisely achieved the DC voltage from 0 to $100 \mathrm{mV}$. On the characteristic record, the measurement temperature was $670^{\circ} \mathrm{C}$ (Fig. 11).

Conditions of measurement:

- Work-piece material: 20CrMo5,

- Model hob milling tool material: HS6-5-2-5,

- Cutting speed: $\mathrm{v}_{\mathrm{c}}=98,25 \mathrm{~m} / \mathrm{min}$,

- Axial feed: $\mathrm{f}_{\mathrm{a}}=2 \mathrm{~mm} / \mathrm{rev}$,

- $\quad$ Tangential feed: $\mathrm{f}_{\mathrm{t}}=1,25 \mathrm{~mm}$.

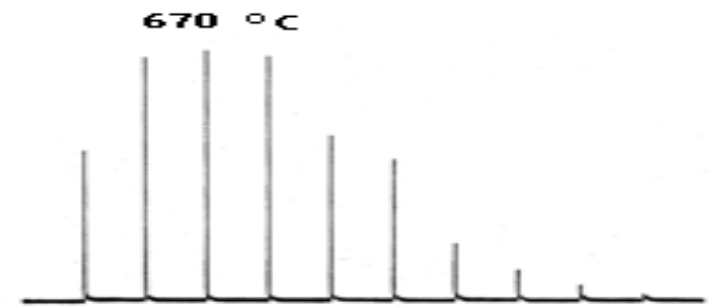

Fig. 11. Characteristic record of measured cutting temperature
In the future, the described method will be further improved and it will be possible reach to the basic principles on which the layout of the heat sources and the character of the temperature fields in the tooth of the model hob milling tool, the work-piece and the chip is based.

\section{Conclusion}

Improving the hob milling process is important and useful both for gear manufacturers and for manufactures of hob milling tools. Increasing the efficiency of the gear cutting of cylindrical gears is one of the basic directions for the development of modern gears. Hob milling is an efficient process for the gear cutting of high quality cylindrical gears.

The developed method of direct measurement of temperature in the gear cutting of cylindrical gears with straight teeth by model hob milling tool enabled the signal recording.

\section{Acknowledgments}

The research was funded by the Ministry of Education, Science and Technological Development of the Republic of Serbia, within the projects TR 35015 and III 43008, and it is also the result of the cooperation within CEEPUS project CIII-RO-0058-07.

\section{References}

1. A. Antoniadis, N. Vidakis, N. Bilalis, Fatigue fracture investigation of cemented carbide tools in gear hobbing, J. Manuf. Sci. Eng. 124 (4), 784-791 (2002)

2. V. Dimitriou, N. Vidakis, A. Antoniadis, Advanced computer aided design simulation of gear hobbing by means of three-dimensional kinematics modeling, $J$. Manuf. Sci. Eng. 129 (5), 911-918 (2007)

3. K. D. Bouzakis, E. Lili, N. Michalidis, O. Friderikos, Manufacturing of cylindrical gears by generating cutting processes: A critical synthesis of analysis methods, CIRP Ann. 57, 676-696 (2008)

4. I. Sovilj-Nikić, Modeling and optimization of hob milling process (Modelovanje $i$ optimizacija procesa odvalnog glodanja), Fakultet tehničkih nauka, Novi Sad, Serbia, Doctoral Thesis (unpublished)

5. I. Sovilj-Nikić, B. Sovilj, M. Kandeva, V. Gajić, S. Sovilj-Nikić, S. Legutko, P. Kovač, Tribological characteristics of hob milling tools from economic aspect, J. Balk. Tribol. Assoc. 18 (4), 577-585 (2012)

6. M. Čohodar Husić, Đ. Begić-Hajdarević, A. Čekić, Modern machining systems and industrial robots (Savremeni obradni sistemi i industrijski roboti), Sarajevo: Mašinski fakultet (2014)

7. D. Ješić, Measuring techique (Merna tehnika), Univerzitet Banja Luka, Mašinski fakultet Banja Luka, Republic of Srpska (2004)

8. J. Beno, Theory of metal cutting (Teoria rezania kovov), Srojnicka fakulta TU Košice, Slovakia (1999) 